\title{
The Future of Energy Demand for Freight Transportation: The Impact of China and India
}




\section{About KAPSARC}

The King Abdullah Petroleum Studies and Research Center (KAPSARC) is a non-profit global institution dedicated to independent research into energy economics, policy, technology and the environment, across all types of energy. KAPSARC's mandate is to advance the understanding of energy challenges and opportunities facing the world today and tomorrow, through unbiased, independent, and high-caliber research for the benefit of society. KAPSARC is located in Riyadh, Saudi Arabia.

\section{Legal Notice}

(C) Copyright 2018 King Abdullah Petroleum Studies and Research Center (KAPSARC). No portion of this document may be reproduced or utilized without the proper attribution to KAPSARC. 


\section{Key Points}

hina and India's movement of freight have in recent decades produced a significant increase in energy demand. Economic shifts and population growth in these two countries have played a major role in driving this development. The right data and a better knowledge of the trends that are shaping the freight movement are prerequisite steps to understanding the primary determinants of the rapidly rising oil consumption by these two most important emerging economies.

Factors that might accelerate demand for freight include:

- Economic development initiatives such as China's Belt and Road Initiative and the Indian Ocean Rim Association, which will affect both the domestic movement of freight in these countries and global patterns of trade.

- Trends in consumer behavior and lifestyle through the development of e-commerce and changes in economic structure driven by government policies, which may have major implications for both inland and far ocean freight transport.

Offsetting these factors are;

- the slowing pace and restructuring of Chinese economic growth.

- The 'Uberization' of freight transport that might lead to efficiencies through reduced empty run miles.

Priority policy actions include building strong structural regimes to improve the energy efficiency of prime movers (trucks, trains, etc.), and logistics planning (routing, load aggregation, etc.), which create a basis for incorporating other technology improvements. 


\section{Summary for Policymakers}

The economic growth in China and India during the last two decades has led to a significant increase in their freight transportation energy demand, with major implications for the global fuel markets. Among the fundamental forces driving this change is both countries' entry into the global production and trade system, which has transformed them into economic powerhouses and major exporters of manufactured goods and services to the international market. Rapidly rising income, growing domestic markets supported by the enthusiastic participation of the population, and active government policies have further boosted economic growth and fostered domestic prosperity. This has led to increased demand for raw materials, energy commodities, intermediate goods and final products that are moved by ships, trucks and trains - and this ultimately translates into demand for oil, accounting for nearly half of global transportation energy demand growth in the last ten years.

As the Chinese economy cools down and settles into a new normal rate of growth while the world economy continues to recover from the financial crisis, what does the future hold for Chinese and Indian freight transportation energy demand? Three trends point to potential strong growth in freight transportation:

Although China's economic transition in recent years has been focused on slowing down infrastructure development and reducing excess industrial capacity domestically, the country's Belt and Road Initiative, with its emphasis on infrastructure investment, may have substantial implications for freight transportation.
In the meantime, the Indian economy has continued its strong growth in recent years. This is expected to boost manufacturing and construction sector growth, potentially generating strong demand for freight movement.

At the micro level, the latest trends in consumer behavior, such as online shopping, with the corresponding demand for lighter and faster product delivery, will increasingly change the way goods are currently moved between producers, distributors and end-users, and may also lead to greater freight distribution demand.

Offsetting these trends, technology innovations in the freight transportation sector, such as the 'Uberization' of freight mobility, could potentially result in substantially improved logistics efficiency and energy savings through reduced empty run miles.

To generate insights into the potential impacts of these new trends will require new approaches. While policymakers and researchers have largely focused on personal mobility and urban infrastructure, freight transportation research has received much less attention and has suffered from limited data availability, especially in countries like China and India, and this ultimately affects policymaking. Consequently, understanding the gaps in freight transportation data, together with the use of new methods such as data collection using information and communication technologies to address the gaps, will assist policymakers to better comprehend the disruptions that may occur in global fuel markets. 


\section{Background to the Workshop}

hina and India have experienced remarkable economic growth and development over the last 30 years. In 2015, China became the world's largest economy, measured in purchasing power parity, while India became the world's fastest-growing emerging economy. As a result, transportation energy consumption, both for personal mobility and for freight movement, has surged in these countries. The outlook for personal mobility and the competition to internal combustion engine power trains is well documented, even if there is a wide divergence in the predicted outcomes. The energy consumed in the movement of freight, however, is less widely researched.

Rapid economic growth and the development of the global supply chain have resulted in China and India becoming the most important freight transportation sector energy consumers after the United States. We define freight transportation to include the movement of raw materials and goods for intermediate or final consumption. Unlike personal mobility, with its potential mode shifts from private vehicles to public transit and fuel switching from fossil fuel powered vehicles to electric vehicles, freight transportation seems more likely to rely on diesel fuel, which is harder to displace. Diesel is expected to overtake motor gasoline as the world's dominant transportation fuel in the coming years as freight sector demand continues to grow.

This workshop helped advance research on the future of freight sector transportation energy demand in China and India by focusing on topics that included:

Data availability and modeling of freight movement, including global supply chains and international linkages.

The continued economic shift towards Asia and freight energy demand, centered on India and China.

Major 'game-changing' developments in the future of freight energy demand, such as e-commerce, 3D printing, or changes in economic structure.

The impact of economic development initiatives such as China's Belt and Road Initiative and the Indian Ocean Rim Association. 


\section{Current and Future Changes Shaping the Movement of Freight in China and India}

ne of the most important sectoral consumers of oil is freight transportation on road. It is responsible for about half of global demand for diesel. With the current momentum of economic growth in China and India, their consumption of road freight transport energy will continue to increase, and is expected to account for the majority of net increase in global road freight oil demand.

Efficiency trends in freight movement are highly correlated with both the size and structure of an economy's gross domestic product. An increase in income per capita in a country usually leads to a switch of vehicle usage from medium freight trucks (MFTs) to heavy freight trucks (HFTs), since HFTs provide the most efficient road freight transport. In China, the trucking sector is the largest commodity carrier and freight transport energy consumer. The use of trucks in Indian road freight movement is growing fast, but rail is also trying to satisfy the increasing demand. Personal income growth and transportation technology market penetration, including progress in using alternative fuels, are expected to continue their contribution in shaping these activities.

In both China and India, e-commerce is a key driver of demand for freight transportation, with the volumes of goods and products bought and sold through online platforms increasing significantly. This is accentuated by the effect of 'express shipping' on road freight movement. Logistics networks have rapidly expanded in China, where the business-to-consumer segment is the biggest e-commerce growth area. Beijing, the capital city, alone accounts for 13.5 percent of national total online shopping. In the meantime, e-commerce in rural regions has also exhibited strong growth in recent years. According to the Ministry of
Commerce, this reflects rising incomes and greater access to online markets.

The rapid development of information and communication technology has, in recent years, offered an effective method for improving freight transport efficiency. Uber's successful 'passengertaxi matching' business model has inspired similar 'freight-truck matching' innovations in the freight transport sector. Connecting freight service customers with individual truckers digitally, the 'Uberization' of freight can potentially provide large efficiency gains through reducing empty runs and various other overheads, especially in developing countries like China, where the freight transportation sector is very fragmented and freight information distribution can be costly. Moreover, improved road conditions that enable better use of GPS, together with better communication technology data, will have an impact on increasing vehicle speed and mileage.

These developments provide an important opportunity for policymakers to develop a nationwide strategy and national targets to improve the economic efficiency of freight transportation. In China, with its inland waterways and distant ocean ports, the development of different freight transportation modes has been systematic and planned. In India, there is a central policy for freight transportation port development, which includes specific tariffs that are set by the central body, the Tariff Authority for Major Ports (TAMP). However, different ports have different standards and tariffs relating to variations in financing, costs and cargo tonnages. Ports in India are developing at different rates based on their costs and efficiency. The informal transport market, especially India's trucking industry, also needs to be considered when drawing up a holistic plan for the transportation sector. 


\section{Challenges in Data Collection and Freight Transportation Modeling}

n order to identify the key determinants of freight growth so as to evaluate road freight fuel consumption and make future freight dynamics projections, the selection of appropriate models and high-quality data for modeling freight transportation are both critical. As China and India are quickly becoming the world's largest transportation energy consumers, more effort is needed to establish comprehensive freight transportation databases for these two nations. Depending on data availability, a variety of low- to high-resolution models can be applied to model freight transportation.

Generally speaking, low-resolution models have less stringent data requirements and can be consistently applied to multiple countries, where the required data are available and can be easily harmonized. By contrast, since highresolution models are more data intensive, and may demand more detailed information such as freight commodity breakdown, collecting these data are associated with large costs and these models tend to be limited to the Organization for Economic Cooperation and Development (OECD) countries. For many developing economies, including China and India, there has been a lack of such detailed freight information, specified by commodities and transportation modes. Therefore, one of the primary challenges to building in-depth freight transportation models lies in successfully identifying satisfactory data sources.

Another reason for collecting detailed freight information, particularly by commodity breakdown, is that it is a good indicator of the basic structure of an economy. It can also provide pointers for policy development, which can be an important driver of freight movement in rapidly growing economies. For instance, recent economic development in China and India has been supported by institutional reforms and economic structural changes which, in turn, have considerably fueled freight transportation growth. A good example is China's decision to join the World Trade Organization, which has not only helped transform the economy into a global powerhouse and shifted its economic focus to manufacturing but has also greatly boosted its freight activity.

An advantage of the 'Uberization' of freight movement is that the digital platform and smart on-vehicle equipment make it possible to collect detailed information about both the freight cargo and the vehicle, thus offering a cost-effective alternative to the conventional survey approach of data collection. With less well-developed infrastructure and fewer institutions for disseminating and collecting freight information, China and India could achieve great benefits by capitalizing on this opportunity.

Some other possible considerations for the future include making available more concrete data, taking a closer look at open and shared global transportation logistics systems, modernizing the modes of transport and using satellite data as a method to increase efficiency and lower energy demand.

Capturing and understanding trends and economic activities will help provide a framework for policymakers in both China and India to better identify where action could be needed to reduce energy consumption or where there might be room for improvement in freight activity. 


\section{About the Workshop}

APSARC convened the workshop in September 2017 with some 25 experts

in the areas of transportation, freight, shipping, rail, environment, academia and policy to facilitate a discussion on the future of freight transportation energy demand in China and India. The workshop was held under a modified version of the Chatham House rule by which participants consented to be listed below. However, none of the content in this briefing is attributable to any individual attendee.

\section{List of Participants}

Shahad Albardi - Research Analyst, KAPSARC

Dr. Saurabh Bandyopadhyay - Economist, National Council of Applied Economic Research (NCAER)

Pierpaolo Cazzola - Transport Researcher, International Energy Agency (IEA)

Dongmei Chen - Research Fellow, KAPSARC

Sylvain Cote - Program Director, KAPSARC

Ravi Gadepalli - Research Scholar, Indian Institute of Technology

Wenke Han - Director, National Development and Reform Commission (NDRC)

Paul Kishimoto - Transport Researcher, Massachusetts Institute of Technology (MIT)

Liancheng Li - Deputy Director, Institute of Comprehensive Transport, NDRC

Dr. Brantley Liddle - Senior Research Fellow, Energy Studies Institute, National University of Singapore (NUS)
Nora Nezamuddin - Senior Research Analyst, KAPSARC

Xunmin Ou - Professor, China Automotive Energy Research Center

Punit Oza - General Manager, Bulk and Freight, Klaveness Asia

Tiandou Peng - Researcher, Tsinghua University

Shri Prakash - Distinguished Fellow, The Energy and Resources Institute (TERI)

Jitendra Roychoudhury - Research Fellow, KAPSARC

Dr. Nahla Samargandi - Assistant Professor of Economic Growth, King Abdulaziz University

Zhiyu Tian - Deputy Director, Energy Research Institute (ERI), NDRC

Nicholas Wagner - Analyst, International Transport Forum, OECD

Tianpeng Wang - Researcher, Tsinghua University

Yanjia Wang - Professor, US-China Green Energy Council

Dr. Xun Xu - Research Associate, KAPSARC

Xinjun Zhou - Deputy Director, China Academy of Railway Sciences

Yuezhong Zhu - Division Chief for International Cooperation, ERI, NDRC 


\section{About the Team}
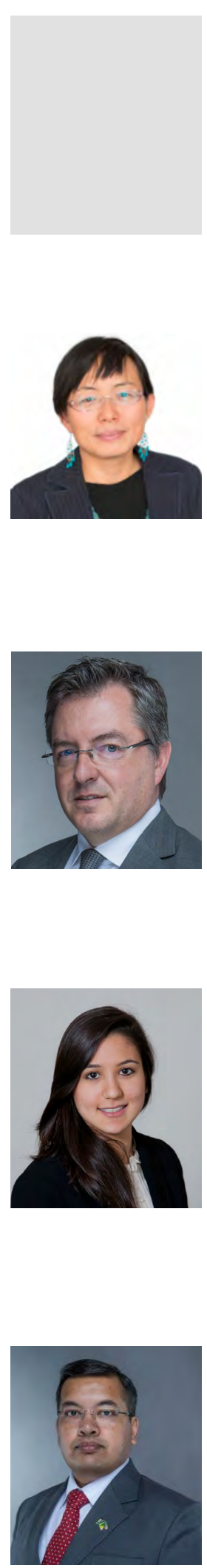

\section{Shahad Albardi}

Shahad is a research analyst at KAPSARC, currently working with the research operations team. She has conducted research on energy policy, particularly regarding the interaction between renewable energy and conventional fuels. She holds a Bachelor of Science in electrical and computer engineering from Effat University in Jeddah, Saudi Arabia.

\section{Dongmei Chen}

Dongmei is a research fellow at KAPSARC focused on China-related policy study and partnership coordination. She has more than 20 years working experience in the energy and climate field in China, acting as head of the Institute of Industrial Productivity China Office and director of the Climate Change and Energy Program for WWF China before she joined KAPSARC.

\section{Sylvain Côté}

Sylvain is the program director for Energy Demand, Efficiency and Productivity at KAPSARC. He previously worked at the Organization for Economic Co-operation and Development and the North American Commission for Labor Cooperation.

\section{Nora Nezamuddin}

Nora is a senior research analyst focusing on transport economic policy and modeling. She holds a Bachelor of Science Business Administration and international relations from the American University in Washington, D.C.

\section{Jitendra Roychoudhury}

Jitendra is a research fellow at KAPSARC working on global coal and India energy research projects. He previously worked in consulting, advising organizations on commodity flows and markets. 


\section{Xun Xu}

Xun is a research associate working on KAPSARC's China/India future freight transport energy demand project. His research interests include freight transportation, development economics, population economics and the Chinese economy.

\section{About the Project}

The objective of the project is to analyze the economic, institutional and policy determinants of freight transport energy demand in China and India. Both countries have witnessed strong freight-related energy consumption growth in the past decades due to their robust economic performance, and are expected to continue to account for the majority of the world's transportation oil consumption growth in the coming decade. Additionally, both countries are top importers of crude from Saudi Arabia. Therefore, this project explores current markets and future scenarios of transportation energy consumption in China and India with policy relevant insights. Specifically, the project focuses on freight movement demand drivers among freight transport modes, and freight transport modal choice and energy efficiency technology. This work provides an opportunity to study the best practice in transport planning to serve the needs of new infrastructure development and more efficient domestic transport energy consumption in Saudi Arabia. 
Notes

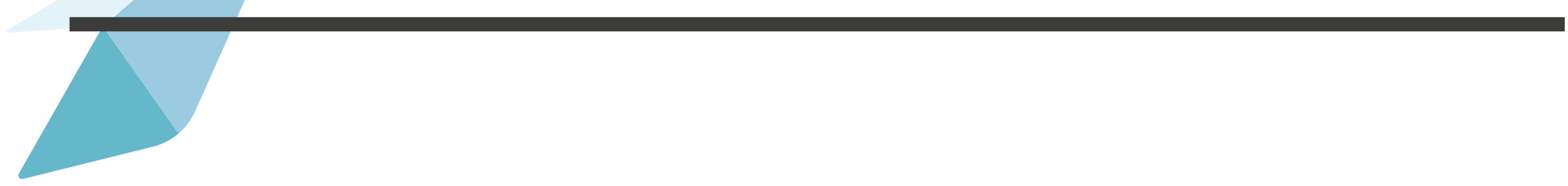


INAPSARC

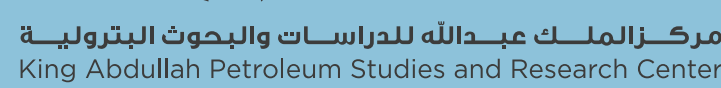

www.kapsarc.org 